CBIE-LACLO 2015

Anais do XXI Workshop de Informática na Escola (WIE 2015)

\title{
Aprendizagem Móvel e Multimídia: a produção de material pedagógico na perspectiva BYOD
}

\author{
Maristela Compagnoni Vieira $^{1}$, Débora Conforto ${ }^{2}$ \\ ${ }^{1}$ PPGIE/UFRGS; Faculdade de Pedagogia - Cesuca/INEDI - Porto Alegre - \\ Cachoeirinha - RS - Brazil \\ ${ }^{2}$ Colégio Assunção, Rede Marista - Porto Alegre - RS - Brazil \\ \{maricompagnoni, deboraconforto\} @gmail.com
}

Resumo. O uso de tecnologias móveis - smartphones, conexão Wi-Fi, $Q R$ Codes -, e os princípios orientadores da Aprendizagem Móvel, das Teorias da Carga Cognitiva e da Aprendizagem Multimídia foram consorciados para organizar um material de enriquecimento com o objetivo de subsidiar a produção de textos argumentativos-dissertativos de estudantes do Ensino Médio. Os resultados da pesquisa de abordagem qualitativa reafirmaram os dispositivos móveis como símbolo identitário de adolescentes, evidenciaram suas vantagens quanto à ubiquidade, à pervasividade e sua inserção no cotidiano escolar, confirmando o potencial pedagógico de uma estratégia de Aprendizagem Móvel na construção do pensamento argumentativo.

\section{Mobile and Multimedia Learning: the production of pedagogical materials in BYOD perspective}

\begin{abstract}
The use of mobile technology - smartphones, Wi-Fi, QR Codes - and the guiding principles of Mobile Learning, Cognitive Load Theories of Cargo and Multimedia Learning were combined to organize an enrichment material for the purpose of subsidizing the production of dissertative-argumentative texts of high school students. The results of the qualitative research reaffirmed the mobile devices as an identity symbol of adolescents, they showed their advantages in terms of ubiquity and pervasiveness and their place in everyday school life, confirming the pedagogical potential of a Mobile Learning strategy in the construction of argumentative thought.
\end{abstract}

\section{Introdução}

Entre as diferentes configurações que a Informática Educativa vem assumindo nas primeiras décadas do Século XXI, as abordagens baseadas no uso de um dispositivo móvel por aluno (um para um, ou 1:1), são aquelas que têm recebido mais atenção por parte de decisores políticos e gestores de tecnologia educacional em diferentes países da América Latina (Lugo e Shurman, 2012). Embora as abordagens 1:1, em geral, baseiem-se na distribuição ou aquisição de dispositivos homogêneos para utilização na escola e em casa, também emerge em alguns contextos a configuração que se populariza sob a sigla BYOD (Bring Your Own Device, ou seja, traga seu próprio dispositivo), que explora as tecnologias heterogêneas dos próprios estudantes para finalidades diversas, dentre as quais se destacam os smarthphones.

As propostas na dimensão BYOD, entretanto, colocam alguns desafios aos professores, tais quais: a grande divergência tecnológica dos equipamentos; o potencial limitado de processamento de texto característico de dispositivos de tela tátil; o tamanho reduzido das telas para leitura de materiais extensos ou com fontes pequenas e não ajustáveis, 
entre outras questões. Nesse sentido, embora seja possível contar na atualidade com uma ampla gama de materiais educacionais digitais em rede, caracterizado por Weller (2011) como a "Pedagogia da Abundância", tais recursos digitais frequentemente não estão de acordo com princípios que os tornariam mais usáveis, adaptáveis e acessíveis a dispositivos móveis com telas e poder de processamentos reduzidos, como também quanto à observação dos pressupostos teóricos voltados ao atendimento das características da cognição humana em processos de aprendizagem multimídia.

Diante desse contexto, este estudo apresenta uma experiência brasileira de desenvolvimento de material pedagógico estático e multimídia, por meio do consorciamento de recursos como smartphones, Internet móvel, material impresso e $Q R$ Codes, esses últimos compreendidos como tecnologias que imprimem botões virtuais em qualquer substrato físico, permitindo a inserção de conteúdo multimídia em materiais estáticos como, por exemplo, um texto impresso. Gabriel (2013) nomeia tal recurso digital como mobile tags, códigos de barra bidimensionais que possibilitam codificar links para a Internet que podem ser escaneados por aplicativos disponíveis a equipamentos móveis.

Este documento foi organizado apresentando inicialmente os princípios orientadores da Aprendizagem Móvel, das Teorias da Carga Cognitiva e da Aprendizagem Multimídia, que, juntamente com os pressupostos de usabilidade e acessibilidade para equipamentos de tela tátil, compõem o arcabouço teórico que sustenta o desenvolvimento do material de enriquecimento pedagógico proposto. Na sequência, demonstra-se a concretização dos conceitos norteadores para a elaboração do material e sua aplicação junto a estudantes do Ensino Médio, revelando a percepção dos sujeitos envolvidos quanto ao material proposto e aos limites e possibilidades da abordagem em apoio a processos de aprendizagem na perspectiva BYOD.

\section{Aprendizagem Móvel}

A progressiva redução dos custos de equipamentos tecnológicos de uso pessoal e a profusão de tecnologias móveis nas primeiras décadas do Século XXI começaram a desenhar um novo panorama para a Informática educativa, não mais estabelecido a partir da escassez de recursos. Conceitos de mobilidade e de conectividade têm estabelecido as condições de possibilidade para romper com o discurso que institui o Laboratório de Informática como o lugar por excelência para a tecnologia na escola. No eixo da nova gama de recursos tecnológicos utilizáveis nas escolas e nas universidades, podemos citar os notebooks, lousas digitais interativas, celulares, smartphones e tablets.

Às novas configurações espaçotemporais para a tecnologia somam-se a progressiva fartura de recursos digitais e a súbita abundância de conteúdo e sistemas de aprendizagem impulsionada pela virtualização e pelo armazenamento em nuvem. Assim, na medida em que o conteúdo torna-se digital, a perspectiva da escassez tende a desaparecer, condicionando outros desafios para capitalizar essas novas possibilidades tecnológicas em ações de inovação também para o processo pedagógico. A Pedagogia da Abundância (WELLER, 2011) de recursos e de conteúdos físicos e digitais, aliada à evolução dos serviços de conexão móvel com a Internet, ao armazenamento em nuvem e ao enriquecimento dos aparelhos de telefone celular promovem o surgimento de uma nova modalidade de educação, a Aprendizagem Móvel (Mobile Learning, ou mlearning), considerada por alguns pesquisadores como um novo estágio da aprendizagem multimídia assistida por computador, capaz de transformar formas mais tradicionais do processo educacional (PU et al., 2011; LUZ e FONSECA, 2013; SENA, OLIVEIRA E CARVALHO, 2014). 
Nesse sentido, três conceitos colocam-se na centralidade da compreensão desse novo paradigma de aprendizagem: ubíqua (disponível em qualquer lugar); pervasiva (transparente e integrada às atividades cotidianas); ambiente (naturalmente entrelaçada ao entorno educacional). Contudo, é importante considerar que a Aprendizagem Móvel, apresenta-se simultaneamente personalizada e integrada ao contexto da sala de aula, com potencial para manter os estudantes mais conectados e vinculados a atividades colaborativas (KUKULSKA-HULME, TRAXLER, 2005). Os dispositivos que operam por esse paradigma requerem materiais e ambientes adaptados às suas especificidades, com conceitos claros, objetivos, curtos e imagéticos (CARRILLO-RAMOS, 2012; NIELSEN, BADIU, 2014).

\section{BYOD: na contramão das teorias de difusão da tecnologia na educação}

Ao longo das últimas décadas, diferentes configurações marcaram a inserção das Tecnologias de Informação e Comunicação (TICs) na educação, com foco inicial nos computadores de mesa (desktops), deslocando-se posteriormente para os computadores portáteis (netbooks) e, mais recentemente, tablets (LUGO, SCHURMANN, 2012). Nessa perspectiva, três configurações de inserção tecnológica em contextos educacionais podem ser caracterizadas:

(1) Laboratório de Informática: Computadores dispostos em uma única sala de aula, com utilização atrelada ao agendamento prévio. Esse desenho para a inserção da tecnologia projeta computadores para muitos alunos e com o tempo de exploração/interação restrito e partilhado, caracteriza o que Conforto (2014) denominou como a Lógica da Escassez. Em alguns casos, a sala dos professores e a biblioteca são equipadas com computadores, com o objetivo de ampliar as oportunidades de trabalho independente para professores e alunos. A principal vantagem desse modelo reside na economia permitida pela aquisição de um menor número de equipamentos, dada a natureza compartilhada da tecnologia.

(2) Computador de mesa na sala de aula: Emerge de esforços, como analisam Lugo, Schurmann (2012), para alinhar a política de TIC com as prioridades e currículo de ensino. As próprias salas de aula são equipadas com um ou dois computadores, tornando-os mais acessíveis aos alunos e aos professores como recurso para as atividades diárias. Embora o acesso ao computador, nesse caso, seja limitado, dada a proporção entre número de estudantes e computadores, esse modelo amplia as possibilidades de integração das TIC no currículo, especialmente para uso em trabalhos de grupo, uma vez que professores podem planejar aulas e trabalhos por equipes, apoiados por esse recurso digital.

(3) Abordagem 1:1: Dispositivos homogêneos adquiridos pela instituição: $O$ mais recente modelo caracteriza-se pela distribuição ou utilização de um dispositivo de tecnologia móvel para cada aluno e professor. A principal desvantagem desse modelo relaciona-se ao alto custo destinado à compra de equipamentos individualizados e a encargos associados à formação dos professores, à manutenção dos equipamentos, à conectividade, entre outros, conforme analisaram Valiente (2010) e Warschauer e Ames (2010). Laboratório Móvel: A escola organiza um ou vários conjuntos de laptops ou tablets em carrinhos móveis, geralmente suficiente para 25-30 alunos. Como no modelo do Laboratório de Informática, os recursos são limitados, por isso, os professores precisam planejar com antecedência e reserva-los para aulas específicas. Durante a aula, no entanto, os alunos são capazes de usar dispositivos em um ambiente de 1: 1. BYOD: Privilegia a utilização dos dispositivos dos próprios estudantes. Esse modelo não apresenta custos elevados para as instituições ou governos e, ainda, pode contribuir com os processos de subjetivação de jovens, que tem no celular um dos seus principais símbolos identitários (BALARDINI, 2008). Entretanto é importante destacar que iniciativas que privilegiam a utilização dos dispositivos dos próprios estudantes revelam-se menos adequadas a instituições situadas em comunidades de baixa renda, sobretudo quando um dos objetivos da ação seja a redução da exclusão sociodigital.

Nos últimos anos, o modelo 1: 1 tornou-se cada vez mais difundido e tem sido o foco principal de diversas políticas públicas e privadas de inserção das TICs na educação. Os 
gestores de instituições públicas e privados parecem não mais discutir se o modelo é digno de investimento, mesmo quando os escassos estudos na área apresentam resultados pouco conclusivos acerca dos benefícios diretos e indiretos de tais iniciativas (WARSCHAUER e AMES, 2010, VALIENTE, 2010). A análise de casos de sucesso e de insucesso deve balizar a tomada de decisão para a escolha da tecnologia que poderá operar como um recurso com o potencial de transformar as oportunidades e os resultados educacionais. Por isso, a importância de garantir o acesso individual à tecnologia e a materiais ajustados às características físicas dos equipamentos, ao estilo de aprendizagem dos estudantes e do acesso à Internet.

\section{Multimídia e Cognição Humana}

Contemporaneamente, os estudantes são confrontados com informações em diferentes formatos: som, texto, imagens, gráficos, animações. Essa combinação de informações pode provocar uma sobrecarga cognitiva, quando o volume da carga é superior à capacidade de compreensão humana. A Teoria da Carga Cognitiva discutida por Sweller (2003) apresenta um conjunto princípios que buscam minimizar recursos mentais desnecessários, maximizando o processo cognitivo à resolução de problemas. Para esse autor, a aprendizagem será possibilitada e potencializada se a forma de apresentar a informação estiver alinhada com o processo cognitivo humano.

$\mathrm{O}$ aumento e a variedade de materiais digitais de natureza educacional não tem sido acompanhado de uma elaboração mais cuidadosa desses recursos para que os mesmos possam promover uma aprendizagem significativa. A Teoria da Aprendizagem Multimídia (MAYER e MORENO, 2002) estabelece que o ser humano percebe a informação por meio de dois diferentes canais de processamento, representados pelos modos verbal e pictórico. O resultado da combinação das informações obtidas pelos dois diferentes canais com os conhecimentos prévios do sujeito será transformado em conhecimento e armazenado na memória de longo prazo (Figura 1).

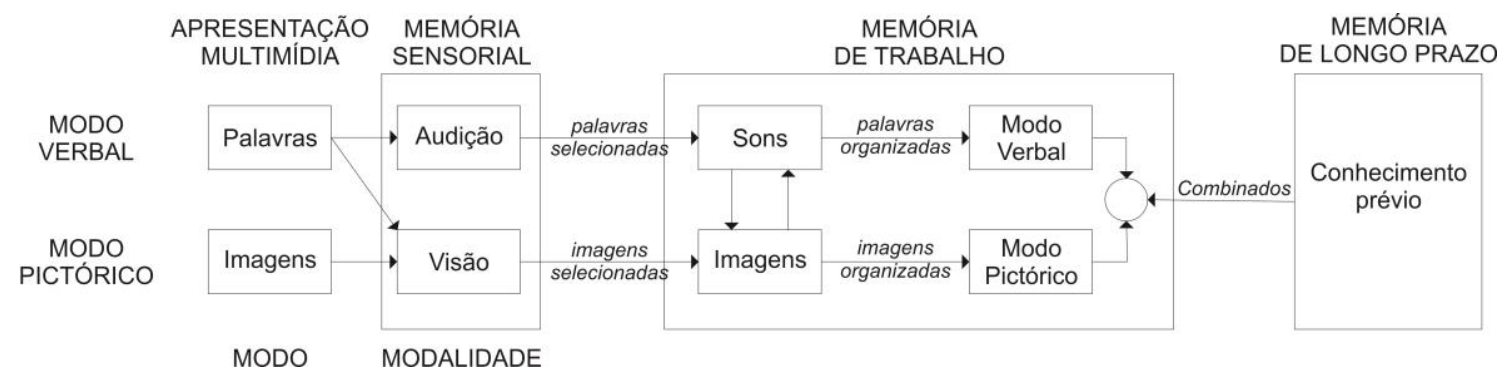

Figura 1 - Teoria Cognitiva da Aprendizagem Multimídia (Mayer e Moreno, 2002 adaptado)

Como analisa Mayer (2001), aplicações multimídias geralmente exploram mais de um canal de percepção simultaneamente, o que pode gerar uma sobrecarga cognitiva e provocar um processo de desorientação e de desestímulo do estudante. Para Sweller (2003) a elaboração de conteúdo para mediar processo de aprendizagem devem observar três principais tipos de carga cognitiva: (1) intrínseca, revelada pela complexidade do conteúdo apresentado pelo material/recurso educacional; (2) natural/relevante, imposta pela atividade pedagógica e necessária para a concretização do objetivo da aprendizagem; (3) extrínseca/externa, não impacta o processo de aprendizagem, condicionando desperdício de recursos mentais limitados que poderiam ser utilizados para minimizar a carga cognitiva intrínseca. Reconhecendo que a 
capacidade de processamento mental é limitado, a utilização de recursos multimídia deve buscar uma maior equidade dessas cargas para que o processo de aprendizagem seja eficiente (Figura 2).

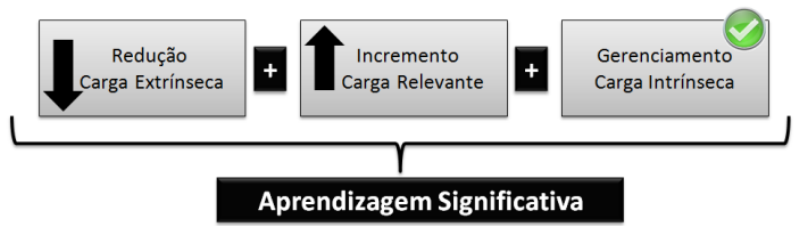

Figura 2 - Esquema de balanceamento das cargas cognitivas

Partindo desses pressupostos, Mayer e Moreno (2002) desenvolveram um conjunto de diretrizes aplicáveis ao desenvolvimento de materiais voltados à aprendizagem por meio de sistemas computacionais, apresentadas no Quadro 1.

\section{Quadro 1 - Resumo dos princípios da Teoria da Aprendizagem Multimídia}

Princípio da Contiguidade: animações e narrações devem ser apresentadas de maneira complementar e contígua.

Princípio da Coerência: elementos como palavras, imagens ou sons estranhos ou desnecessários competem com o conteúdo relevante nos canais de processamento cognitivo.

Princípio da Modalidade: a apresentação de animações e textos escritos de maneira concomitante pode sobrecarregar a memoria de processamento visual.

Princípio da Redundância: uma animação narrada concisa pode ser menos efetiva à aprendizagem quando se inclui texto escrito concomitante.

Princípio da Multimídia: animações narradas são mais efetivas para a aprendizagem do que apenas narrações. Princípio das Diferenças individuais: estudantes com maior nível de conhecimento e com maior grau de concentração espacial, possuem maiores condições de organização e de processamento da informação.

Fonte: Mayer e Moreno, 2002 (adaptado).

De maneira geral, depreende-se dos princípios estabelecidos por Mayer e Moreno (2002) que estudantes aprendem mais significativamente quando suas memórias de trabalho, visual e/ou verbal não estão sobrecarregadas e também quando os canais de processamento visual e verbal são igualmente estimulados em uma relação síncrona de correspondência e contiguidade. A observância desses princípios, aliados a uma interface simples, eficiente e atrativa, resulta em recursos digitais mais adequados à mediação de aprendizagens significativas.

Os materiais multimídia, ao serem acessados por dispositivos móveis, necessitam contemplar as diretrizes de usabilidade móvel (NIELSEN e BADIU, 2014) e as recomendações do Guia de Boas Práticas em Web Móvel (W3C, 2008). Os limites de tempo para a realização da atividade, o perfil dos estudantes e a qualidade do acesso à Internet foram aspectos respeitados na organização e no gerenciamento da atividade, com atenção especial às seguintes questões (Quadro 2):

\section{Quadro 2 - Princípios de Acessibilidade e Usabilidade para dispositivos móveis}

\begin{tabular}{|c|l|}
\hline $\begin{array}{c}\text { Facilitação à entrada } \\
\text { de dados }\end{array}$ & $\begin{array}{l}\text { Em dispositivos de tela pequena, a entrada de dados é prejudicada, especialmente } \\
\text { para a digitação, que costuma ser lenta e repleta de erros. }\end{array}$ \\
\hline $\begin{array}{c}\text { Minimização do } \\
\text { tempo de download }\end{array}$ & $\begin{array}{l}\text { A maioria dos usuários não apresenta paciência para aguardar um longo tempo } \\
\text { para a carga da página. }\end{array}$ \\
\hline Rotulação de dados & $\begin{array}{l}\text { A rotulação dos dados, com legendas (ou lables) claras, facilita a navegação no } \\
\text { espaço físico e hipertextual a que se referem, contribuindo para a localização e } \\
\text { prevenção de erros. }\end{array}$ \\
\hline
\end{tabular}



consegue visualizar menos dados ao mesmo tempo.

Fonte: Nielsen e Badiu (2014); W3C (1998).

\section{Metodologia}

A dificuldade evidenciada por 69 estudantes, do $1^{\circ}$ ano do Ensino Médio, em uma escola privada, de Porto Alegre, em propor argumentos consistentes na escrita de textos dissertativos, projetou o escopo da pesquisa: analisar a contribuição da tecnologia móvel e a produção de material didático adequado a equipamentos de tela tátil em ações de enriquecimento multimídia para a definição da tese e para a qualificação da exposição argumentativa. Entre as interfaces tecnológicas que compuseram o cenário de investigação destacam-se: fórum de discussão (plataforma Moodle), smartphones com conexão móvel e aplicativos para a leitura de $Q R$ Codes.

Metodologicamente, configura-se como uma pesquisa de abordagem qualitativa, de objetivo explicativo, empregando a técnica de análise textual discursiva, conforme proposta por Moraes (2003). A investigação estruturou-se em etapas, consecutivas e complementares, voltadas: (a) ao desenvolvimento do material enriquecimento multimídia adequado à smartphones e (b) à coleta e à análise dos dados referentes à percepção dos estudantes quanto à validade e à contribuição do conteúdo acessado pelos celulares.

\section{0 material de enriquecimento multimídia para smartphones}

Por conduzir uma investigação que analisa as possibilidades de qualificar a produção textual com o suporte de conteúdo multimídia, o material proposto como mediador da estratégia de enriquecimento passou a ser também parte do objeto de estudo, configurando-se como dado no corpus textual da análise e das discussões dos resultados. Na Figura 3, possibilita-se o acesso ao material de enriquecimento multimídia para smartphones desenvolvido pelas autoras deste estudo, com base nos marcos teóricos anteriormente descritos.

Os princípios de Usabilidade e Acessibilidade Móveis (NIELSEN e BADIU, 2014; W3C, 1998), foram contemplados por meio das estratégias para maximizar e otimizar o acesso ao conteúdo multimídia:

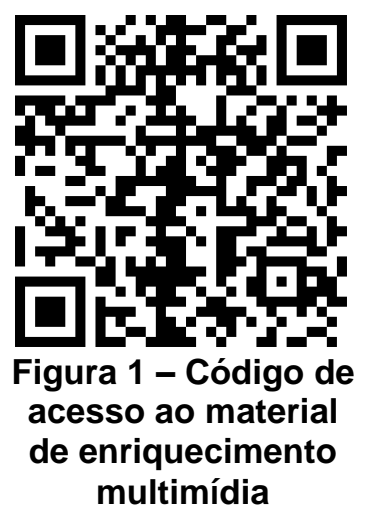

(1) Facilitação à entrada de dados pelo escaneamento de links associados a $Q R$ Codes, suprimindo a necessidade de o usuário digitar informações; (2) Minimização do tempo de download pelo particionamento dos vídeos selecionados, com duração máxima de 4 minutos e resolução reduzida, garantindo, entretanto, a compreensão das imagens e das legendas, como também, foram disponibilizados materiais em diferentes formatos (vídeos, animações, imagens e textos), permitindo aos sujeitos com conexões mais lentas a opção por recursos que exigissem menos tráfego de dados; (3) Rotulação dos dados associados aos $Q R$ Codes, de maneira a informar a natureza do material e o conteúdo que continham, permitindo, assim, a escolha segundo o interesse e a disponibilidade de conexão; (4) Adequação dos textos ao tipo de dispositivo pela objetividade conquistada pela organização da informação em blocos, com linhas curtas, para permitir a eliminação das barras de rolagem e para cansar menos o usuário, aumentando a capacidade de compreensão. 
A diversidade de conteúdo multimídia - charges, animações, vídeos, imagens, textos curtos e objetivos - foi selecionada com vistas a responder aos desafios colocados pelas características cognitivas da aprendizagem humana, de maneira geral, e as identitárias, dos sujeitos pesquisados. A opção por elementos não unicamente textuais alicerça-se na teoria de Mayer e Moreno (2002), por afirmarem que são mais facilmente decodificadas informações que associam narração e imagem em movimento, e também Pertktold (2003), ao analisar que uma das fragilidades das gerações contemporâneas à televisão e à Internet reside na dificuldade em ler e compreender conteúdo textual, o que condicionou uma maior adesão ao conteúdo multimídia. O conteúdo multimídia ao ser acessado pelo smartphone referendou a opção tecnológica identificada por Balardini (2008) como o símbolo identitário dos adolescentes.

A análise da incidência na utilização de cada tipo de recurso na aplicação do material de enriquecimento multimídia, representada no Gráfico 1, elucida as discussões de Mayer e Moreno (2002) e Perktold (2003), ao demonstrar a maior adesão aos conteúdos de natureza visual e narrativa, como charges, vídeos e animações, que concentraram $71 \%$ dos acessos. Os materiais de processamento unicamente verbal, tais quais textos e dicionário, foram menos expressivos, com incidência de $29 \%$.

\section{Gráfico 1 - Incidência de adesão aos recursos multimídia}

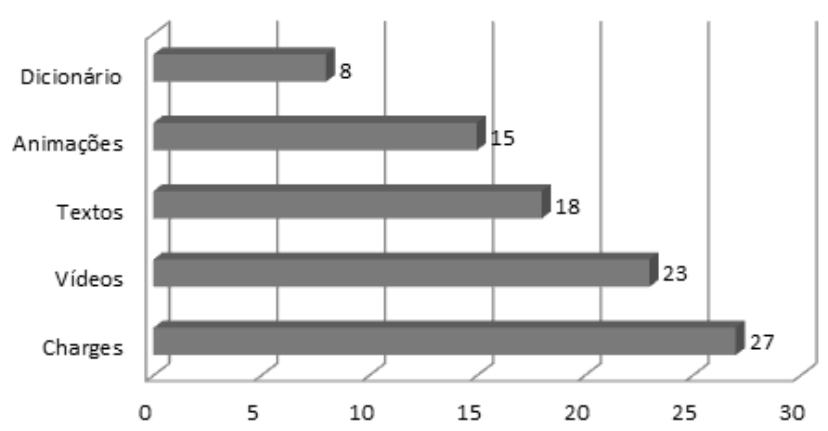

Fonte: Dados da pesquisa

Considerou-se, também, na elaboração do material de enriquecimento multimídia entregue aos estudantes participantes deste estudo o conjunto de orientações elencado por Chandler e Sweller (1991), que visam facilitar a memorização e a apropriação da informação. Dentre essas recomendações, destaca-se o cuidado na formatação do texto, com o uso de fontes sem serifa, e na centralização títulos (Figura 4, número 1), bem como no alinhamento à esquerda dos textos mais longos (Figura 4, número 2).

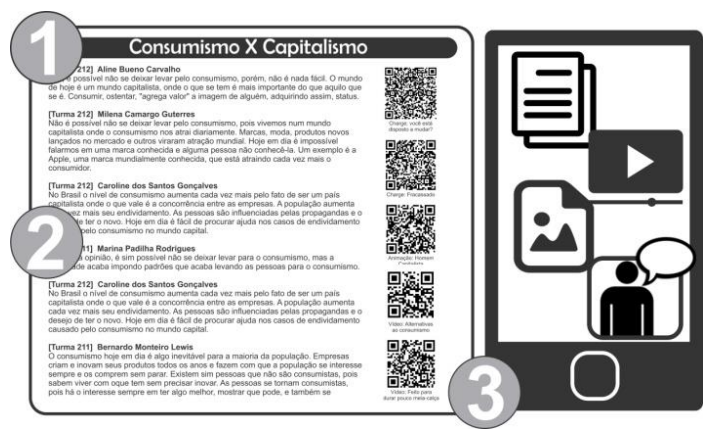

Fonte: Dados da pesquisa

Figura 4: Recorte explicativo do material de enriquecimento multimídia 
O Princípio das Diferenças Individuais, de acordo com Sweller (2003), e que remete à constatação da diversidade humana, foi considerado ao apresentar materiais em diversos formatos (modos verbal e não verbal), com liberdade para ajuste da forma à modalidade auditiva ou visual, com a possibilidade de parar, pausar e voltar às informações associadas aos $Q R$ Codes e acessadas individualmente por meio dos smartphones dos estudantes (Figura 4, número 3).

A associação do texto à imagem estática ou em movimento a ser visualizada no dispositivo móvel faz referência ao Princípio da Contiguidade Espacial e Temporal (SWELLER, 2003), uma vez que aprendizagens mais significativas podem ocorrer quando elementos verbais e pictóricos evidenciam uma efetiva correspondência entre o tempo e o espaço de sua apresentação. A importância do Princípio da Coerência (SWELLER, 2003) foi revelada pelos estudantes quanto à categorização das 130 postagens mensagens do fórum de discussão, pois quanto mais simples for a informação a ser transmitida, mais facilmente esta será assimilada. A categorização dos depoimentos em grupos semânticos reduziu o número de postagens, permitindo eliminar a carga cognitiva excessiva, estranha ou desnecessária, otimizando o gerenciamento da carga cognitiva intrínseca, inerente à dificuldade associada à atividade de escrita de textos dissertativos (Gráfico 2).

\section{Gráfico 21 - Fórum de discussão: postagem total e por categorias}

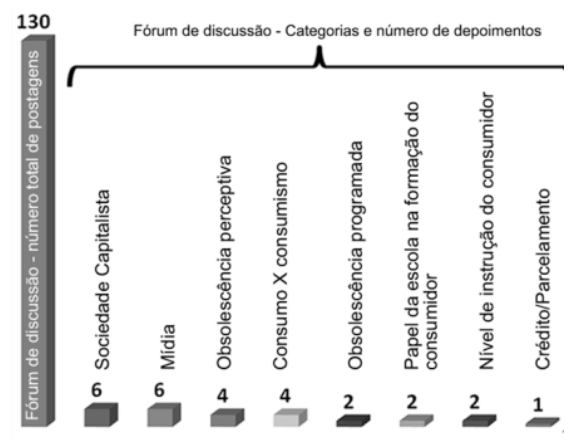

\subsection{Análise da percepção dos sujeitos quanto à proposta de enriquecimento multimídia}

"Podemos ter uma economia de papel, apenas em um quadradinho pode ser escaneado um texto longo... imagina, até um livro!"; "Como é fácil acessar a informação, pesquisar!"; "Já estamos acostumados a usar o celular, a escola não pode ser uma zona de sombra, um empecilho."; "Antes não era possivel usar calculadora, os tempos mudaram."; "Com essa estratégia, foi mais fácil construir o texto.", "o celular pode ser uma maneira nova de aprendizado em aula, basta saber como e para que utilizar.". Essas narrativas dos estudantes sujeitos desta pesquisa reafirmaram a relevância do escopo da pesquisa e impulsionaram a análise dos dados.

Os estudantes envolvidos na investigação evidenciaram o potencial dos $Q R$ Codes para a qualificação da construção argumentativa em textos dissertativos. Excertos de considerações dos sujeitos de pesquisa evidenciam essa percepção positiva da estratégia: "Essa proposta foi muito boa, pois na hora de fazer uma redação, o que nos prejudica é a falta de boas ideias para desenvolver os argumentos.".

$\mathrm{Na}$ forma de organização do material de enriquecimento multimídia, dois aspectos foram percebidos pelos estudantes participantes da pesquisa, evidenciando a concretização do objetivo estabelecido, apoiar a construção de argumentos em textos 
dissertativos: (1) a proximidade espaço-temporal pela categorização das reflexões estabelecidas no fórum de discussão em relação à temática da proposta de escrita e (2) a associação das categorizações projetadas ao conteúdo multimídia vinculado aos $Q R$ Codes.

A análise da narrativa dos sujeitos de pesquisa quanto à adesão aos recursos do material de enriquecimento multimídia reflete a validade da estratégia, posto que $94 \%$ dos estudantes envolvidos declararam ter se apropriado do conteúdo multimídia para a realização da tarefa - "Naquele dia, eu e minha dupla vimos vídeos que foram essenciais para realizar o trabalho". Outro elemento significativo, a partir da percepção dos sujeitos quanto à estratégia, diz respeito à mobilidade e a conectividade possibilitadas pelo dispositivo móvel: "com o celular a gente não precisa sair da sala de aula para usar a Internet", "É muito melhor trabalhar com o celular na sala de aula do que subir para a Informática".

O celular, na dinâmica da sala de aula, imprimiu na ação pedagógica a marca da heterogeneidade. A presença de diferentes mídias e o acesso aos recursos da Internet afirmou a singularidade de cada estudante para romper com o "tamanho único" que tradicionalmente caracteriza o planejamento educacional e, assim, valorizar e respeitar a variedade de interesses e de estilos de aprendizagem, "é bem mais fácil fazer as atividades cada um com o seu próprio material, além de mais divertido".

\section{Considerações Finais}

A estratégia de Aprendizagem Móvel apresentada deu visibilidade às possibilidades de desterritorializar a tecnologia, retirando a exclusividade do Laboratório de Informática como o espaço autorizado para o uso da linguagem digital; rompendo com a rigidez da delimitação espaço-temporal no gerenciamento do uso da tecnologia na escola, que tem sido mantida mesmo com a presença de dispositivos móveis - tablets e smatphones.

Teorias como a da Carga Cognitiva e da Aprendizagem Multimídia ofertaram um conjunto de pressupostos que conduziu a organização do material apresentado aos estudantes, mas também as discussões sobre a forma de estruturá-lo na perspectiva de enriquecimento multimídia. Celulares nas salas de aula alteram o padrão de acesso à rede, deslocando o ponto de acesso estabelecido pelas portas seriais e os cabos USB, para a quase onipresença do ambiente de acesso. Esse paradigma, de um usuário que deixou de ir até a rede e que desfruta dos benefícios da rede que vai até ele, vivenciado pelo estudante contemporâneo presente nas escolas brasileiras, em especial nas privadas, necessita ser percebido pelos gestores e educadores.

Os resultados desta investigação relevam a viabilidade do celular no enriquecimento em praticas de aprendizagem móvel, tanto no incremento da argumentação em textos dissertativos, foco de análise deste estudo de caso; quanto na percepção dos estudantes que atuaram como sujeitos de pesquisa. O celular operou como uma interface catalisadora, para instigá-los a lidar com seu próprio aprendizado e para engajá-los em práticas de construção de conhecimento coletivo. Foi pela interface dos smartphones, símbolo identitário dos adolescentes, que a proposta pedagógica foi projetada para, quem sabe, apontar caminhados de qualificação do Ensino Médio, uma etapa do processo de escolarização caracterizada pela falta identidade.

\section{Referências}

BALARDINI, S. (2008) De deejays, floggers y ciberchabones: subjetividades juveniles y tecnocultura. In: BENDIT, R.; HAHN, M.; MIRANDA, A. (Ed.). Los jóvenes y el 
futuro: procesos de inclusión social y patrones de vulnerabilidad en un mundo globalizado. 1. ed. Buenos Aires: Prometeo Libros.

CARRILLO-RAMOS, A. et al. (2012) Enriching services using agents in mobile environments. Multimedia Computing and Systems (ICMCS), IEEE.

CHANDLER, P.; SWELLER, J. (1991) Cognitive Load Theory and the Format of Instruction. Cognition and Instruction, 8 (4), p. 293-332.

CONFORTO, D. (2014) Um exercício na cultura da participação. In: DANTAS, L.G.; MACHADO, M.J. (orgs). Tecnologias e Educação: perspectivas para gestão, conhecimento e prática docente. São Paulo: FTD, p. 161 - 168.

GABRIEL, M. (2013) Educ@r: a (r)evolução digital na educação. SP: Saraiva.

KUKULSKA-HULME, A.; TRAXLER, J. (2005) Mobile Learning: A handbook for educators and trainers. London: Routledge.

LUGO, M. T.; SCHURMANN, S. (2012) Turning on mobile learning in Latin America: illustrative initiatives and policy implications. Paris: UNESCO.

LUZ, J.; FONSECA, L. (2013) EduConnect: uma ferramenta de apoio à aprendizagem colaborativa para dispositivos móveis em redes MANET. Anais do XXIV Simpósio Brasileiro de Informática na Educação (SBIE)

MAYER, R. E.; MORENO, R. (2002) Aids to computer-based multimedia learning. Learning and Instruction, v. 12, p. 107-119.

MORAES, R. (2003) Uma tempestade de luz: a compreensão possibilitada pela análise textual discursiva. Ciência Educação, Bauru, SP, v. 9, n. 2, p. 191-210.

NIELSEN, J.; BADIU, R.. (2014) Usabilidade Móvel. RJ: Elsevier.

PERKTOLD, C. (2003) Ensaios de Pintura e de Psicanálise. Internacional: BH.

PU, H.; LIN, J.; SONG, Y.; LIU, F. (2011) Adaptive Device Context Based Mobile Learning Systems. International Journal of Distance Education Technologies, v. 09, n. 01, p. $44-56$.

SENA, D., OLIVEIRA, E, CARVALHO, L. (2014) Aplicativos móveis para o aprendizado de matemática. Anais do XXV Simpósio Brasileiro de Informática na Educação (SBIE).

SWELLER, J. (2003) Cognitive Load Theory: A Special Issue of educational Psychologist. LEA, Inc.

VALIENTE, O. (2010) 1-1 in Education: Current Practice, International Comparative Researsh Evidence and Policy Implications. OECD Education Working Papes, n. 44.

W3C. (2008) Mobile Web Best Practices 1.0. Basic Guidelines W3C Recommendation 29 July. Disponível em: <http://www.w3.org/TR/mobile-bp/>. Acesso em 10 out. 2014.

WARSCHAUER, M.; AMES, M.. (2010) Can one laptop per child save the world's poor?. Journal of International Affairs, v. 64, n. 1.

WELLER, Martin. A pedagogy of abundance. Spanish Journal of Pedagogy, 249 pp. 223-236, 2011. 